\title{
CORRECTION
}

\section{Correction to: A possible postsynaptic role for SNAP-25 in hippocampal synapses}

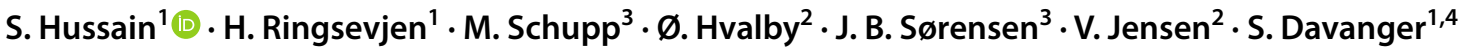

Published online: 2 January 2019

(c) Springer-Verlag GmbH Germany, part of Springer Nature 2019

\section{Correction to: Brain Structure and Function https://doi.org/10.1007/s00429-018-1782-2}

In the original publication of the article the author name M. Schupps was incorrect.

The correct name of the author is: M. Schupp. The original article has been corrected.

Publisher's Note Springer Nature remains neutral with regard to jurisdictional claims in published maps and institutional affiliations.

The original article can be found online at https://doi.org/10.1007/ s00429-018-1782-2.

S. Davanger

svend.davanger@medisin.uio.no

1 Division of Anatomy, Department of Molecular Medicine, Institute of Basic Medical Sciences, University of Oslo,

Oslo, Norway

2 Division of Physiology, Department of Molecular Medicine, Institute of Basic Medical Sciences, University of Oslo, Oslo, Norway

3 Department of Neuroscience, Faculty of Health and Medical Sciences, University of Copenhagen, Copenhagen, Denmark

4 Laboratory of Synaptic Plasticity, Division of Anatomy, Institute of Basic Medical Sciences, P.O.Box 1105,

0317 Blindern, Oslo, Norway 